\title{
A Study of Clinicosocial profile of young female hypertensives in a tertiary care hospital
}

\author{
Mausumi De 1,Amitabha Chattopadhyay 2 ,Kanak Kumar Mitra 3, \\ PrasantaRay Karmakar 4,Indrajit Mondal 5, Sanjay Seth 6 \\ 1 (Assistant Professor, Department of Pharmacology,R.G.Kar Medical College, West Bengal, India) \\ 2(Assistant Professor, Department of Community Medicine, R.G.Kar Medical College ,West Bengal, India) \\ 3(Associate Professor, Department of Cardiology, R. G.Kar Medical College, West Bengal, India) \\ 4(Associate Professor, Department of Community Medicine, R. G.Kar Medical College ,West Bengal, India) \\ 5(Clinical Tutor,Department of Cardiology,R.G.Kar Medical College West Bengal, India) \\ 6(GDMO, Raigunj Sadar Hospital,Uttar Dinajpur, West Bengal, India)
}

\begin{abstract}
Background: One of major contributing factors for the growing burden of cardiovascular disorders is increasing prevalence of hypertension and involvement of younger people. Despite its high prevalence in the population, hypertension in women has received less attention than hypertension in men. The primary objective of this study was to assess the sociodemographic and clinical profile of young female hypertensives. Methodology: This was a cross sectional study carried out in the Cardiology OPD of a tertiary care hospital in Kolkata, West Bengal. Six forty six young female hypertensives patients (aged between 20 to $<40$ years) were interviewed and their blood pressure was measured. Results: The mean systolic blood pressure and mean diastolic blood pressure was $144.1 \pm 24.6 \mathrm{mmHg}$ and $79.9 \pm 12.4 \mathrm{mmHg}$ respectively. Newly detected hypertensives were $21.4 \%$, out of which $39.1 \%$ were stage 1 hypertensives and $60.9 \%$ were stage 2 .Conclusion: Though men are more commonly affected by hypertension, a significant number of females are also affected. By modification of lifestyle, diets, regular exercise and by use of appropriate drugs at right time, majority of hypertensive cases in females specially in the young age group of below 40 years can be controlled and thus major complications can be prevented.
\end{abstract}

Keywords: Hypertensives, young females, clinicosocial profile

\section{Introduction}

According to World Health Report 2002, cardiovascular diseases (CVDs) will be the largest cause of death and disability by 2020 in India. In 2020 AD, 2.6 million Indians are predicted to die due to coronary heart disease which constitutes $54.1 \%$ of all CVD deaths. Nearly half of these deaths are likely to occur in young and middle aged individuals (30-69 years) ${ }^{1}$. Hypertension, though a common medical problem in the elderly, is not limited to the elderly population, but also involves younger people. As the prevalence of hypertension is seen to be rising in younger individuals, more and more information regarding the profiles of young hypertensives is needed. In 2002, the age-adjusted prevalence of hypertension was 30\% in men and $34 \%$ in women ${ }^{2}$. In India, the awareness of hypertension, its risk factors and complications is very poor. Scanty information is available regarding the prevalence of hypertension and its complications in younger Indians. Despite its high prevalence in the population, hypertension in women has received less attention than hypertension in men. ${ }^{3-5}$

The primary objective of this study was to assess the clinicosocial profile of young female hypertensives for gaining better insight of the factors related to this disease process.

\section{Materials and Methods}

This was a cross sectional study carried out in the Cardiology Outpatient Department of R.G. Kar Medical College, a tertiary care hospital in Kolkata, West Bengal over a period of 6 months from December 2010 to May 2011. After obtaining necessary permission from institution ethical committee, all young female hypertensives patients(aged between 20 to $<40$ years) attending the Cardiology OPD during this period were selected $(\mathrm{n}=646)$.Selected subjects were either newly detected hypertensives or previously detected hypertensives on medications or without medications; critically ill hypertensive patients and prehypertensives were not included in this study. The purpose of the study was explained to them; informed verbal consent was taken and they were interviewed using a predesigned and pretested questionnaire(after translation to local language) to extract basic socioeconomic and demographic information, and their prescriptions were scrutinized for relevant clinical information's like presenting complaints, complication suffered etc; information regarding diabetes and dyslipidemia were also included in case of those patients where relevant prescriptions and lab reports were found. Hypertension was defined as per JNC 7 guidelines (Normal: Systolic and diastolic < 120/80,Prehypertensives: systolic 120-139 or diastolic 80-89 mm of Hg,Stage-1 hypertensives: systolic 140-159 
or diastolic 90-99 mm of Hg,Stage-2 hypertensives: systolic 160 or diastolic $100 \mathrm{~mm} \mathrm{of} \mathrm{Hg})^{6}$ and was measured using the auscultatory method with a standardized calibrated mercury column type sphygmomanometer and an appropriate sized cuff encircling at least $80 \%$ of the arm in the seated posture, with feet on the floor and arm supported at heart level; two separate measurements were done and the average of the two measurements was recorded. In some cases, where high blood pressure was recorded for the first time, the researchers checked the blood pressure more than twice and took the average of the two close readings. Standing height and weight were measured. Body weight was measured (to the nearest $0.5 \mathrm{~kg}$ ) with the subject standing motionless on the weighing scale, feet about $15 \mathrm{~cm}$ apart, and weight equally distributed on each leg. Subjects were instructed to wear minimum outerwear (as culturally appropriate) and no footwear while their weight was being measured. Height was measured (to the nearest $0.5 \mathrm{~cm}$ ) with a portable stadiometer, with the subject in an erect position against a vertical surface, and with the head positioned so that the top of the external auditory meatus was level with the inferior margin of the bony orbit. The body mass index (BMI) which is expressed in $\mathrm{kg} / \mathrm{m}^{2}$ was used to define obesity and overweight according to recommendations as given by World Health Organization. Waist circumference was measured at the midpoint between the inferior margin of the last rib and the top of the iliac crest. Hip circumference was measured at the largest posterior extension of the buttocks. Waist and hip circumferences were measured to the nearest $0.1 \mathrm{~cm}$. The waist-to hip ratio was calculated using the formula, WHR = waist circumference $(\mathrm{cm}) /$ hip circumference $(\mathrm{cm})$. Physical activity was coded into the following categories: sedentary (walking, job involving desk work, mainly domestic activities, viewing television, or reading); moderate level of physical activity (home maintenance activities, gardening, feeding cattle or livestock, washing linen/clothes by hand, carrying firewood, etc.); heavy or greater level of physical activity (agricultural work in fields, pulling a cart or rickshaw, quarry work, cycling; rowing; carpentry; masonry, etc). New cases were defined as those cases who had never been previously diagnosed as hypertensives or had never consumed any hypertensive drugs. Statistical analysis was done by using Microsoft Excel 8.0 and Medcalc 11.4 software.

\section{Results}

The mean age of the selected patients was $34.1 \pm 4.69$ years. The mean systolic blood pressure and mean diastolic blood pressure was $144.1 \pm 24.6 \mathrm{mmHg}$ and $79.9 \pm 12.4 \mathrm{mmHg}$ respectively.

Table 1 presents the socio demographic profile of the selected patients. Majority of the patients belonged to the age group (30- $<40$ years), while $76 \%$ were from urban areas. Patients were mainly Hindus while women with $>2$ child were lesser in number. About $75 \%$ of the subjects were educated up to secondary level of education, while majority were housewives. Physical activity of most of the women were sedentary in nature while $56.2 \%$ of the women had a family income of ‘4151- ‘6918 as per modified Kuppuswamy’s scale(2010).Majority were non vegetarian, and consumed excess salt( $>5 \mathrm{gm} /$ day). Family history of hypertension was present in $36.2 \%$ of the participants. Addiction to any form of tobacco(chewable \& non chewable)/alcohol/both and history of oral contraceptive use were present in $8.97 \%$ and $13.3 \%$ of the subjects respectively.

Table-2 presents the clinical profile of the selected young female hypertensives. Newly detected hypertensives were $21.4 \%$, out of which $39.1 \%$ were stage 1 hypertensives and $60.9 \%$ were stage 2 .More the $50 \%$ of the participants were either overweight/obese, while waist hip ratio(WHR) were $>0.85$ in $64.1 \%$ of the subjects. Commonest initial presenting complain were nonspecific (in $67.9 \%$ of the subjects) followed by headache, breathlessness. Diabetes was present among $12.1 \%$ of the women $(\mathrm{n}=478)$, while $33.5 \%$ were dyslipidemic $(\mathrm{n}=498)$. Major complications were ischemic heart disease $(4.95 \%)$ and renal complications. About $65 \%$ of the patients were having two or three antihypertensive drugs.

Figure 1\&2 presents the comparison between the median, quartiles, maximum, minimum systolic and diastolic blood pressures of the two different age groups(20- $<30 \& 30-<40$ years), waist hip ratio categories( $<0.85 \&$ $>0.85)$ and BMI categories $\left(<25 \mathrm{~kg} / \mathrm{m}^{2} \& \geq 25 \mathrm{~kg} / \mathrm{m}^{2}\right)$ by Box and Whisker plots respectively. Variations were found which can be further tested for association in future studies.

\section{Discussion}

There is a continuous, strong, and graded relation between blood pressure and cardiovascular disease, but no clear threshold value separates hypertensive patients who will experience future cardiovascular events from those who will not. Hypertension prevalence is lower in the rural Indian population, although there is a steady increase over time here as well. Pooling of epidemiological studies show that hypertension is present in $25 \%$ urban and 10\% rural subjects in India . The prevalence of hypertension increases with age, rising exponentially after thirty years of age ${ }^{2}$. The age-related rise in blood pressure, particularly systolic blood pressure and pulse pressure, contributes substantially to the age-related increase in risk of heart attack, heart failure, and stroke in middle-aged and elderly women. Two unique hypertension-inducing mechanismspregnancy and the use of oral contraceptives - also contribute to the global problem of high blood pressure in women. The pathophysiology of hypertension in women differs in other ways from that in men - women tend 
to have more labile blood pressures and a higher prevalence of the white coat phenomenon ${ }^{7-8}$. Women are more likely to be salt-sensitive; and are more likely to have low renin, high volume hypertension than men ${ }^{9}$. Certain important findings that was found in our study was that nonspecific symptoms and headache being the major presenting symptoms while higher percentage of newly detected cases were having stage 2 hypertesion. WHR and BMI were more than normal in more than half of the subjects. Majority of the females in our study were married, housewives, urban based, having 1-2 child, being nonvegetarian, with sedentary lifestyle and consuming excess salt. However the other factors could be equally important like association of OCP use with elevated pulse pressure as found in "The Enigma study" 10 as well as relation of income, education with hypertension as found in a Korean study ${ }^{11}$. Continuous positive relationship of markers of obesity (body-mass index, waist hip ratio) with major coronary risk factors like hypertension has been shown in many studies ${ }^{12}$.An African study also showed that with increase in parity, SBP increased ${ }^{13}$. Thus, it is important to identify the sociodemographic factors and clinical aspects in relation to hypertension and perhaps this study will help in the initiation of further in-depth analysis of such factors in relation to young female hypertensives, and thereby leading to prevention of hypertension related morbidities.

\section{Conclusion}

Hypertension is a public health and policy problem because of its prevalence, costs and burdens. Though men are more commonly affected by hypertension a significant number of females are also affected. Opportunity to impart health education pertaining to lifestyle modifications was utilized in this study. By modification of lifestyle, diets, regular exercise and by use of appropriate drugs at right time majority of hypertensive cases in females specially in the young age group of below 40 years can be controlled and thus preventing some major complications.

\section{References}

[1] National Cardiovascular Disease Database, Sticker No: SE / 04 / 233208, www.whoindia.org(accessed on July 10,2011)

[2]. Gupta R. Trends in hypertension epidemiology in India. J.Hum Hypertens. 2004;18 (2):73 -8.

[3]. Calhoun DA, Oparil S. The sexual dimorphism of high blood pressure. Cardiol Rev 1998; 6: 356-362.

[4]. Robitaille NM. Hypertension in women.Can J Cardiol 1996; 12 (Suppl D): 6D-8D.

[5]. Kaplan NM. The treatment of hypertension in women.Arch Intern Med 1995; 155: 563-567.

[6]. The Seventh Report of the Joint National Committee on Prevention, Detection, Evaluation, and Treatment of High Blood Pressure: Page 11-12, www.nhlbi.nih.gov(accessed on July 10, 2011)

[7]. Pickering TG. Ambulatory monitoring and the definition of hypertension. J Hypertens 1992; 10: 401-409.

[8]. Myers MG, Reeves RA. White coat effect in treated hypertensive patients: sex differences. J Hum Hypertens 1995; 9: 729-733.

[9]. Hanes DS. Strategies for the treatment of hypertension in postmenopausal women. J Clin Hypertens 1999;1:62-71.

[10]. Hickson Stacey, Miles Karen, McDonnell Barry, Yasmina , Cockcroft John, Wilkinson Ian, McEniery Carmel. Use of the oral contraceptive pill is associated with increased large artery stiffness in young women: The ENIGMA Study. Journal of Hypertension 2011; 29 (6): 1155-59

[11]. Min H, Chang J, Balkrishnan R . Sociodemographic Risk Factors of Diabetes and Hypertension Prevalence in Republic of Korea . International Journal of Hypertension; Volume 2010 (2010): Article ID 410794

[12]. Gupta R, Rastogi P, Sarna M, Gupta VP, Sharma SK, Kothari K .Body-Mass Index, Waist- Size, Waist-Hip Ratio and Cardiovascular Risk Factors in Urban Subejcts. J.Assoc. Physician India 2007; 55: 621-27

[13]. Taylor JY, Chambers AN, Funnell B, Wu CY. Effects of parity on blood pressure among African-American women. J Natl Black Nurses Assoc. 2008 Dec; 19(2):12-9. 


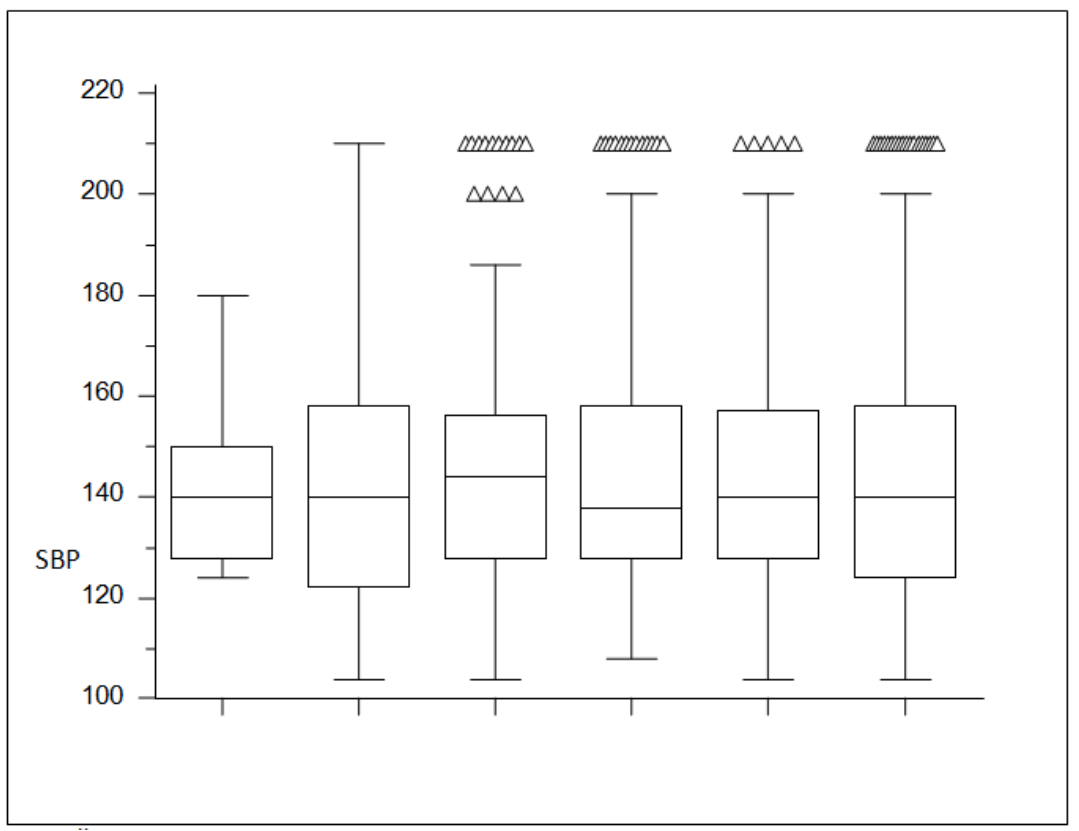

$\Delta=$ outliers

Figure 1: Comparison between the median, quartiles, maximum, minimum systolic blood pressures of the two different age groups, BMI categories and waist hip ratio categories by Box and Whisker plots.

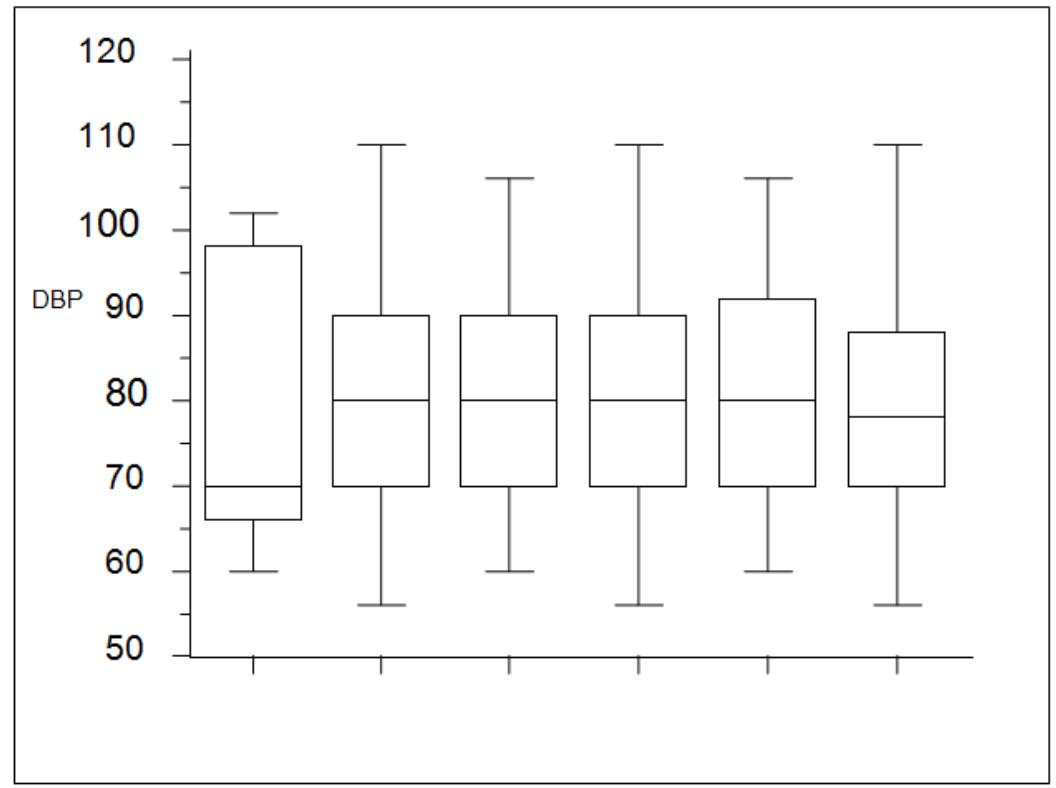

Figure 2 : Comparison between the median, quartiles, maximum, minimum diastolic pressures of the two different age groups, BMI categories and waist hip ratio categories by Box and Whisker plots.

Table-1 : Socio demographic profile of young female hypertensives( $(n=646)$

\begin{tabular}{|lcc|}
\hline $\begin{array}{l}\text { Socio demographic } \\
\text { characteristics }\end{array}$ & No. & percentage \\
\hline Age & 107 & $16.6 \%$ \\
& & $83.4 \%$ \\
$30-<30$ & 539 & \\
Residence & & $76 \%$ \\
Urban & 491 & $24 \%$ \\
Rural & 155 & $78.3 \%$ \\
\hline Marital Status & 506 & \\
Ever married & & \\
\hline
\end{tabular}




\begin{tabular}{|c|c|c|}
\hline Never married & 140 & $21.7 \%$ \\
\hline \multicolumn{3}{|l|}{ Family income per month* } \\
\hline$\leq^{`} 1384$ & 35 & $5.42 \%$ \\
\hline $1385--4150$ & 106 & $16.4 \%$ \\
\hline ‘4151-- 6918 & 363 & $56.2 \%$ \\
\hline '6919--'10,351 & 129 & $19.9 \%$ \\
\hline $10,352 \&$ above & 13 & $2.08 \%$ \\
\hline \multicolumn{3}{|l|}{ Religion } \\
\hline Hindu & 457 & $70.7 \%$ \\
\hline Muslim & 161 & $25 \%$ \\
\hline Others & 28 & $4.3 \%$ \\
\hline \multicolumn{3}{|l|}{ Parity } \\
\hline Nil & 97 & $15.1 \%$ \\
\hline $1-2$ & 425 & $65.8 \%$ \\
\hline$>2$ & 124 & $19.1 \%$ \\
\hline \multicolumn{3}{|l|}{ Education } \\
\hline Illiterate & 23 & $3.5 \%$ \\
\hline Primary & 106 & $16.4 \%$ \\
\hline Middle & 161 & $24.9 \%$ \\
\hline Secondary & 195 & $30.2 \%$ \\
\hline Higher secondary & 96 & $14.9 \%$ \\
\hline Graduate & 65 & $10.1 \%$ \\
\hline \multicolumn{3}{|l|}{ Food habits } \\
\hline Non veg & 545 & $84.4 \%$ \\
\hline Veg & 101 & $15.6 \%$ \\
\hline \multicolumn{3}{|l|}{ Excess salt consumption $\dagger$} \\
\hline Yes & 465 & $72 \%$ \\
\hline No & 181 & $28 \%$ \\
\hline \multicolumn{3}{|l|}{ Family h/o of hypertension } \\
\hline Yes & 238 & $36.8 \%$ \\
\hline No & 408 & $63.2 \%$ \\
\hline \multicolumn{3}{|l|}{ Addiction \# } \\
\hline Yes & 58 & $8.97 \%$ \\
\hline No & 588 & $91.03 \%$ \\
\hline \multicolumn{3}{|l|}{$\mathrm{H} / \mathrm{O}$ of OCP intake } \\
\hline Yes & 86 & $13.3 \%$ \\
\hline No & 560 & $86.7 \%$ \\
\hline \multicolumn{3}{|l|}{ Type of activity } \\
\hline Sedentary & 508 & $78.6 \%$ \\
\hline Moderate & 114 & $17.6 \%$ \\
\hline Hard & 24 & $3.8 \%$ \\
\hline \multicolumn{3}{|l|}{ Occupation } \\
\hline Housewife & 335 & $51.8 \%$ \\
\hline Student & 16 & $2.6 \%$ \\
\hline Govt employee & 67 & $10.4 \%$ \\
\hline Pvt. Employee & 68 & $10.5 \%$ \\
\hline Self employed & 119 & $18.4 \%$ \\
\hline Unemployed & 41 & $6.3 \%$ \\
\hline
\end{tabular}

*as per modified Kuppuswamy's scale(2010)

\# any form of tobacco/alcohol/both

$\dagger$ salt consumption $>5$ gm/daily 
Table-2: Clinical profile of young female hypertensives $(n=646)$

\begin{tabular}{|c|c|c|}
\hline Clinical characteristics & No. & percentage \\
\hline \multicolumn{3}{|l|}{ Time of detection } \\
\hline New cases & 138 & $21.4 \%$ \\
\hline Previously detected & 508 & $78.6 \%$ \\
\hline \multicolumn{3}{|l|}{$\begin{array}{l}\text { Stage of hypertension in } \\
\text { case of new cases }(n=138)\end{array}$} \\
\hline Stage1 & 54 & $39.1 \%$ \\
\hline Stage 2 & 84 & $60.9 \%$ \\
\hline \multicolumn{3}{|l|}{ BMI } \\
\hline Underweight $(<18.50)$ & 75 & $11.6 \%$ \\
\hline Normal(18.5-24.99) & 228 & $35.3 \%$ \\
\hline Overweight $(\geq 25)$ & 255 & $39.5 \%$ \\
\hline $\operatorname{Obese}(\geq 30)$ & 88 & $13.6 \%$ \\
\hline \multicolumn{3}{|l|}{ Waist hip ratio } \\
\hline$<0.85$ & 232 & $35.9 \%$ \\
\hline$>0.85$ & 414 & $64.1 \%$ \\
\hline \multicolumn{3}{|l|}{ Initial presenting complains* } \\
\hline Headache & 94 & $14.6 \%$ \\
\hline Palpitations & 32 & $4.9 \%$ \\
\hline Syncope & 02 & $0.3 \%$ \\
\hline Chest discomfort & 26 & $4.0 \%$ \\
\hline Breathlessness & 44 & $6.8 \%$ \\
\hline Blurring of vision & 06 & $0.9 \%$ \\
\hline Pedal odema & 12 & $1.8 \%$ \\
\hline Cerebro vascular accidents & 02 & $0.3 \%$ \\
\hline Convulsions & 02 & $0.3 \%$ \\
\hline Decreased urine output & 05 & $0.8 \%$ \\
\hline Non specific/ nil symptoms & 439 & $67.9 \%$ \\
\hline \multicolumn{3}{|l|}{ Biochemical findings } \\
\hline Diabetes $(n=478)$ & 58 & $12.1 \%$ \\
\hline Dyslipidemia $(n=498)$ & 167 & $33.5 \%$ \\
\hline \multicolumn{3}{|l|}{ Complications suffered } \\
\hline Ischemic heart disease- & 32 & $4.95 \%$ \\
\hline CVA & 08 & $1.2 \%$ \\
\hline Renal disease & 24 & $3.7 \%$ \\
\hline Eye problem & 18 & $2.8 \%$ \\
\hline \multicolumn{3}{|l|}{$\begin{array}{l}\text { Number of antihypertensives } \\
\text { prescribed }\end{array}$} \\
\hline 1 & 226 & $35.0 \%$ \\
\hline 2 & 298 & $46.1 \%$ \\
\hline$\geq 2$ & 122 & $18.9 \%$ \\
\hline
\end{tabular}

* were mutually inclusive 